\title{
ATIVIDADE PREDATÓRIA DO FUNGO DUDDINGTONIA FLAGRANS SOBRE LARVAS INFECTANTES DE NEMATÓDEOS GASTRINTESTINAIS NO PERFIL DO PASTO EM DIFERENTES NÍVEIS DE INCIDÊNCIA SOLAR
}

\author{
(Predatory activity of the fungus duddingtonia flagrans on infecting larvae of gastrointestinal nematodes at \\ pasture profile in different levels of solar incidence)
}

\begin{abstract}
${ }^{1}$ Barbara Haline Buss Baiak, ${ }^{2}$ Jennifer Mayara Gasparina, ${ }^{2}$ Letícia lanke, ${ }^{1}$ Matheus Deniz, ${ }^{1}$ Karolini Tenffen Sousa, ${ }^{1}$ Letícia Macedo Pereira, ${ }^{2}$ Raquel Abdallah da Rocha, ${ }^{1}$ João Ricardo Dittrich

1Universidade Federal do Paraná, Curitiba, Paraná, Brasil. ²Universidade Estadual de Ponta Grossa, Paraná, Brasil.
\end{abstract}

*Correspondência: barbara_baiak@hotmail.com

RESUMO: O controle biológico é por definição uma estratégia para diminuir as populações parasitárias em níveis aceitáveis, ou seja, que não se tornem prejudiciais ao hospedeiro. A ação se dá através de antagonistas naturais no ambiente como bactérias, artrópodes e fungos, os quais atuam controlando a propagação parasitária (CORREDOR, 2016). Dentre eles, os fungos nematófagos têm demonstrado maior potencial, sendo a espécie Duddingtonia flagrans considerada a mais promissora (WANG et al., 2015). Desta maneira, o objetivo do trabalho foi avaliar a atividade predatória do fungo $D$. flagrans sobre o desenvolvimento de larvas infectantes (L3) em distintos estratos da pastagem sob diferentes incidências solares. O experimento foi realizado no Centro Paranaense de Referência em Agroecologia (CPRA) em Pinhais-PR. Foram utilizadas vinte novilhas da raça Jersey divididas em dois grupos. No grupo tratado os animais receberam $150 \mathrm{~g}$ de pellets em dose única contendo massa micelial $(0.2 \mathrm{~g}$ de micélio) do fungo misturado a $500 \mathrm{~g}$ de concentrado. No grupo controle os animais receberam $150 \mathrm{~g}$ de pellets sem o fungo e $500 \mathrm{~g}$ de concentrado. Após 10 horas da administração do fungo os animais foram direcionados ao piquete experimental onde ficaram das 6:00h até 14:00h. Durante este período foram selecionados ao acaso 10 bolos fecais de animais tratados e 10 bolos fecais de animais controle. Cada bolo fecal foi delimitado e dividido em quatro subdivisões iguais por meio de ligações entre as extremidades. As coletas do pasto foram realizadas por meio das subdivisões, a cada sete dias, totalizando quatro avaliações. Foram coletadas amostras de pasto com distância de $10 \mathrm{~cm}$ do bolo fecal em dois estratos (A:50\% da parte superior da pastagem e B:50\% da parte inferior da pastagem). Para avaliar o efeito da incidência solar na atividade predatória foi medido a cada hora a posição da amostra em relação à incidência solar (permaneceu no sol mais de $50 \%$ do dia ou permaneceu na sombra mais de $50 \%$ do dia). O delineamento experimental utilizado foi em blocos inteiramente casualizados com 2 tratamentos e 20 repetições. Para as análises estatísticas os dados foram transformados em log $(x+1)$ pelo teste Tukey a $5 \%$ de significância. Houve diferença $(P<0,05)$ na recuperação de $L 3$ entre os grupos tanto no estrato A (Controle: 714 L3/kg MS; Tratado: 57,3 L3/kg MS) quanto no estrato B (Controle: 732 L3/kg MS; Tratado 136,6 L3/kg MS) demonstrando a efetividade de predação e migração vertical do fungo. A incidência solar não interferiu $(P>0,05)$ na recuperação de $L 3$ tanto no grupo controle quanto no grupo tratado nos dois estratos avaliados. Contudo pode-se observar uma maior contagem de L3 nas amostras que permaneceram mais de $50 \%$ do dia no sol (Controle A:1063 L3/ $\mathrm{kg} \mathrm{MS,} \mathrm{B:986} \mathrm{L3/kg} \mathrm{MS} \mathrm{/Tratado}$ $\mathrm{A}: 81 \mathrm{L3} / \mathrm{kg} \mathrm{MS}, \mathrm{B}: 150 \mathrm{~L} 3 / \mathrm{kg} \mathrm{MS}$ ) do que nas amostras que permaneceram mais de $50 \%$ do dia na sombra (Controle A: 191 L3/kg MS, B: 350 L3/kg MS/ Tratado: A:0 L3/kg MS, B:104 L3/kg MS). O fungo $D$. flagrans demonstrou ser capaz de suportar o trânsito gastrintestinal e reduzir o número de L3 nos diferentes estratos da pastagem.

Palavras-chave: controle biológico; fungo nematófago; novilha. 


\section{Referências}

CORREDOR, D. J., PULIDO-MEDELIN, M. O., ANAYA, A. M. D. Uso de hongos nematófagos en el control biológico de nematodos gastrointestinales en ovinos. Revista Logos Ciência e Tecnologia, v. 7, n. 2, p. 40-49, 2016.

WANG, B.B. et al. Isolation and characterization of China isolates of Duddingtonia flagrans, a candidate of the nematophagous fungi for biocontrol of animal parasitic nematodes. Journal of Parasitology, v. 101, p. 476-484, 2015. 